\title{
Meningoencefalite granulomatosa em bovinos em pastoreio de ervilhaca (Vicia spp) ${ }^{1}$
}

\author{
Raquel R. Rech², Rafael A. Fighera², Fabiano N. Oliveira² e Claudio S.L. Barros ${ }^{3}$
}

\begin{abstract}
Rech R.R, Fighera R.A., Oliveira F.N. \& Barros C.S.L. 2004. [Granulomatous meningoencephalitis in cattle grazing vetch (Vicia spp] Meningoencefalite granulomatosa em bovinos em pastoreio de ervilhaca (Vicia spp). Pesquisa Veterinária Brasileira 24(3): 169-172. Depto Patologia, Universidade Federal de Santa Maria, 97105-900 Santa Maria, RS, Brazil. E-mail: claudioslbarros@uol.com.br

Granulomatous meningoencephalitis was observed in 7 out of 8 adult dairy cows affected by vetch-associated systemic granulomatous disease, although there was no neurological signs associated with the condition. The cellular inflammatory infiltrates were located in the leptomeninges and as perivascular cuffings within the brain and consisted of epithelioid macrophages, lymphocytes, plasm cells and eosinophils. These inflammatory changes varied from mild to severe from animal to animal and among different brain regions of the same animal. Perivascular cuffings were usually more marked than the leptomeningeal infiltrates. Affected brain regions, in decreasing order of intensity, included diencephalon through the level of massa intermedia, mesencephalon at the level of rostral colliculi, pons and cerebellar peduncles, medulla at the level of obex, frontal lobe at the level of the genu of the corpus callosum, and cerebellum. The character and the distribution of the inflammatory changes are emphasized regarding the differential diagnosis with other diseases and lesions of the bovine central nervous system in the context of the Brazilian surveillance program for bovine spongiform encephalopath.
\end{abstract}

INDEX TERMS: Diseases of cattle, diseases of the central nervous system, meningoencephalitis, plant poisoning, Vicia spp, pathology.

RESUMO.- Meningoencefalite granulomatosa foi observada em 7 de 8 vacas leiteiras adultas afetadas por doença granulomatosa sistêmica associada ao consumo de ervilhaca, embora nenhum dos bovinos afetados apresentasse sinais de distúrbios nervosos. Os infiltrados inflamatórios local izavam-se nas leptomeninges e como manguitos perivasculares no interior do encéfalo; consistiam demacrófagos epitelióides, linfócitos, plasmócitoseeosinófilos. Essas alterações inflamatórias variavam de leves a acentuadas de animal para animal e entre diferentes regiões do encéfalo de um mesmo animal. Geralmente, os manguitos perivasculares eram

\footnotetext{
1 Recebido em 16 de junho de 2004.

Aceito para publicação em 7 de julho de 2004.

Realizado com apoio financeiro do Programa de Apoio a Núcleos de Excelência (PRONEX), Proc. CNPq 661069/1997. Parte da Dissertação de Doutorado do primeiro autor.

2Programa de Pós-Graduação em Medicina Veterinária, área de concentração em Patologia Veterinária, Centro de Ciências Rurais, Universidade Federal de Santa Maria (UFSM).

${ }^{3}$ Departamento de Patologia, UFSM, 97105-900 Santa Maria, Rio Grande do Sul. Email: claudioslbarros@uol.com.br
}

mais acentuados que os infiltrados nas leptomeninges. As regiões do encéfalo afetadas, em ordem decrescente de intensidade, diencéfalo através da massa intermedia; mesencéfalo na altura dos colículos rostrais; ponte e pedúnculos cerebelares, bulbo na altura do óbex, lobo frontal na altura do joelho do corpo caloso e cerebelo. 0 tipo ea distribuição das alterações inflamatórias são enfatizados em relação ao diagnóstico diferencial de outras doenças e lesões do sistema nervoso central de bovinos no contexto do programa brasileiro de vigilância para a encefalopatia espongiforme bovina.

TERMOS DE INDEXAÇÃO: Doenças de bovinos, doenças do sistema nervoso central, meningoencefalite, intoxicação por planta, Vicia spp, patologia.

\section{INTRODUÇÃO}

A forma mais comum de intoxicação pelo consumo de Vicia spp (leguminosas conhecidas popularmente como ervilhaca) em bovinos é caracterizada por dermatite (com alopecia) e doença granulomatosa sistêmica (DGS), que é geralmente referida como DGS ervilhaca-associada (Panciera et al. 1992); a morbidade é de 1\%68\% coeficientes de letalidade oscilam de $50 \%$ a 100\%(Fighera 
\& Barros 2004). Os principais sinais clínicos da DGS ervilhacaassociada incluem dermatite, prurido, diarréia, desidratação, perda de peso, queda na produção de leite, tosse, dispnéia, conjuntivite e febre. A duração do curso clínico pode variar de três dias a cinco semanas, mas usualmente é de duas semanas (Panciera et al. 1966, Panciera 1978, Panciera et al. 1992).

Recentemente surtos de DGS ervilhaca-associada foram diagnosticados em bovinos no noroeste do estado do Rio Grande do Sul (Barros et al. 2001, Fighera \& Barros 2004). Nesses surtos, embora a doença tenha ocorrido com as mesmas características descritas pelos autores mencionados anteriormente, 7 de 8 bovinos necropsiad os apresentaram, meningoencefalite granulomatosa, um aspecto raramente descrito na DGS ervilhaca-associada (Fighera \& Barros 2004). Esse é um achado histopatológico importante no diagnóstico diferencial de doenças do sistema nervoso central (SNC) de bovinos.

O objetivo desse trabalho é descrever os aspectos morfológicos ea distribuição das lesões inflamatórias no encéfalo dos 7 bovinos afetados por DGS ervilhaca-associada. Esse estudo faz parte de uma série que vem sendo realizada em nosso laboratório com a finalidade de documentar lesões e doenças do SNC, a fim de facilitar o diagnóstico diferencial das enfermidades ou lesões do SNC nessa espécie, como parte da vigilância da encefalopatia espongiforme bovina (BSE) coordenada pelo Programa Nacional de Controle da Raiva dos Herbívoros e Outras Encefalopatias (PNCRH) do Ministério da Agricultura Pecuária e Abastecimento (MAPA).

\section{MATERIAL E MÉTODOS}

Os dados epidemiológicos e clínicos foram obtidos durante visitas a 8 propriedades rurais no noroeste do Rio Grande do Sul, onde ocorreram os surtos de DGS ervilhaca-associada. Em cada uma das propriedades foram realizadas duas visitas. Dezessete bovinos foram afetados e 10 foram necropsiados e identificados pelos números de 1-10 (Fighera \& Barros 2004). Todos os animais necropsiados eram vacas de produção leiteira, de raça holandesa, com 5-12 anos de idade (Quadro 1). 0 encéfalo não foi colhido em dois dos 10 bovinos necropsiados. Os 8 encéfalos colhidos foram fixados inteiros em formol a $10 \%$ por duas semanas e 6 litros de solução fixadora foram usados para fixar cada encéfalo. Após a fixação, os seguintes fragmentos do encéfalo foram selecionados para exame histológico: (1) bulbo na altura do óbex, (2) cerebelo, (3) ponte com pedúnculos cerebelares, (4) mesencéfalo na altura dos colícul os rostrais (5) diencéfalo através da massa intermédia e (6) lobo frontal na altura do joelho do corpo caloso e dos núcleos da base (Fig.1). Esses fragmentos foram processados rotineiramente para histologia e corados pela hematoxilina e eosina (HE). 0 infiltrado inflamatório encontrado nas diferentes regiões do encéfalo foi classificado quanto à intensidade como leve $(+)$, moderado $(++)$ ou acentuado $(+++)$. Fragmentos de vários outros órgãos foram colhidos e armazenados em formol a $10 \%$ os detalhes dos métodos de processamento desse material já foram publicados (Fighera \& Barros 2004).

\section{RESULTADOS}

Os detalhes da epidemiologia, dos sinais clínicos e das lesões macro e microscópicas em outros órgãos que não os do SNC, encontram-se em outra publicação (Fighera \& Barros 2004). Resumidamente, o quadro clínico incluía febre, acentuada queda na lactação, espessamento e enrugamento da pele com placas multifocais de alopecia, prurido, conjuntivite, corrimento nasal e ocular, emagrecimento e diarréia. A morbidade média entre os 8 rebanhos afetados (representando uma população de 219 bovinos), foi de $11,1 \%$ o coeficiente de letalidade foi de $100 \%$ e a duração do curso clínico foi de 3-30 dias. Nenhum dos 17 bovinos afetados apresentou quaisquer manifestações clínicas que pudessem ser interpretadas como distúrbios neurológicos. As principais lesões macroscópicas consistiam de nódulos branco-acinzentados, moderadamente firmes, multifocais a coalescentes que infiltravam múltiplos órgãos mas eram mais proeminentes nos linfonodos, adrenal, córtex renal, baço, fígado e miocárdio. Microscopicamente, esses nódulos consistiam de infiltrado inflamatório composto de várias proporções de macrófagos epitelióides, linfócitos, plasmócitos, células gigantes multinucleadas e eosinófilos.

Dos 8 casos em queo encéfal o foi examinado histologicamente, um (Bovino 10) não apresentava alterações. Infiltrado inflamatório deintensidade variável foi observado nas diferentesáreas do encéfalo

Quadro 1. Meningoencefalite granulomatosa em sete bovinos em pastoreio de ervilhaca (Vicia spp). Dados de resenha e epidemiológicos

\begin{tabular}{|c|c|c|c|c|c|c|c|}
\hline \multirow[t]{2}{*}{ Dados } & \multicolumn{7}{|c|}{ Bovinos ${ }^{a}$} \\
\hline & 1 & 2 & 3 & 5 & 6 & 8 & 9 \\
\hline Idade (anos) & 5 & 5 & 5 & 7 & 10 & 8 & 12 \\
\hline Peso $(\mathrm{kg})$ & 500 & 450 & 450 & 400 & 450 & 450 & 450 \\
\hline $\begin{array}{l}\text { Produção de lei- } \\
\text { te (litros/dia) }\end{array}$ & 20 & 6 & 15 & 15 & 12 & 24 & 20 \\
\hline $\begin{array}{l}\text { Espécie de ervi- } \\
\text { Ihaca no pasto }\end{array}$ & V. villosa e V. sativa & V. villosa e V. sativa & V. villosa & V. villosa e V. sativa & V. villosa e V. sativa & V.villosa & V.villosa \\
\hline $\begin{array}{l}\text { Tempo de pasto- } \\
\text { reio na ervilhaca } \\
\text { (meses) }\end{array}$ & 3 & 3 & 4 & 4 & 4 & 2 & 2 \\
\hline $\begin{array}{l}\text { Duração do cur- } \\
\text { so clínico (dias) }\end{array}$ & 15 & 3 & 15 & 15 & 30 & 20 & 19 \\
\hline Tipo de morte & Natural & Eutanásia & Natural & Eutanásia & Natural & Eutanásia & Eutanásia \\
\hline Município (RS) & Giruá & Giruá & Santa Rosa & Tuparendi & Tuparendi & Campo Novo & Braga \\
\hline
\end{tabular}

a Todos os bovinos eram fêmeas da raça holandesa. 

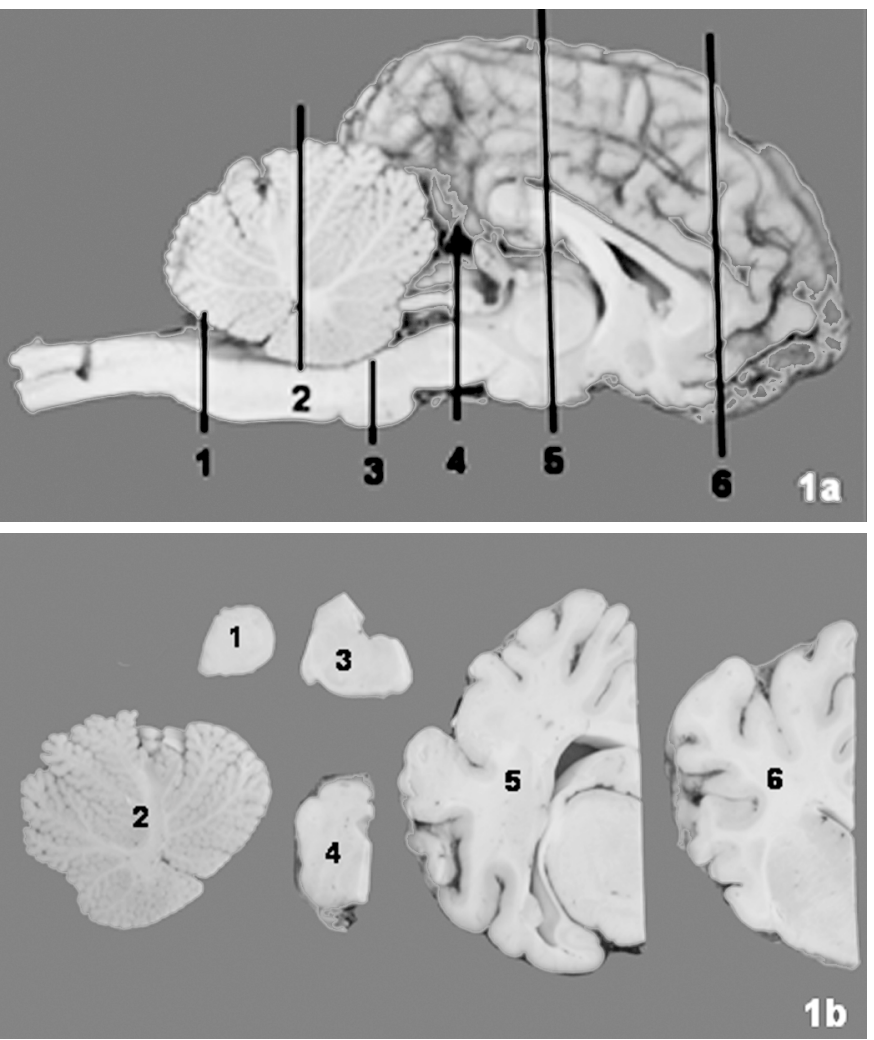

Fig.1. Regiões do encéfalo de onde foram colhidos espécimes para exame histológico nos bovinos com encefalite granulomatosa associada ao pastoreio de ervilhaca (Vicia spp). (A) Hemisfério cerebral mostrando o local dos cortes: 1, bulbo na altura do óbex; 2 , cerebelo; 3 , ponte com pedúnculos cerebelares; 4 , mesencéfalo na altura dos colículos rostrais; 5 , diencéfalo através da massa intermédia e 6 , lobo frontal na altura do joelho do corpo caloso e dos núcleos da base. (B) Seções obtidas dos seis locais mostrados em $A$.

Quadro 2. Distribuição e intensidade da inflamação granulomatosa no encéfalo de sete bovinos intoxicados pela ingestão de ervilhaca

\begin{tabular}{cccccccc}
\hline Área do & \multicolumn{7}{c}{ Bovinos } \\
\cline { 2 - 7 } encéfalo & 1 & 2 & 3 & 5 & 6 & 8 & 9 \\
\hline $1^{\mathrm{a}}$ & $?^{\mathrm{b}}$ & $+\mathrm{c}$ & $?$ & $+++\mathrm{d}$ & $++\mathrm{e}$ & +++ & $?$ \\
$2^{\mathrm{f}}$ & $?$ & ++ & $?$ & +++ & $?$ & ++ & $?$ \\
$3^{\mathrm{g}}$ & $?$ & ++ & $?$ & +++ & ++ & + & + \\
$4^{\mathrm{h}}$ & + & ++ & ++ & +++ & ++ & ++ & + \\
$5^{\mathrm{i}}$ & + & + & ++ & +++ & ++ & +++ & ++ \\
$6^{j}$ & $?$ & $?$ & ++ & +++ & $?$ & ++ & +
\end{tabular}

aBulbo na altura do óbex, bsem lesões, Clesão leve, desão acentuada, elesão moderada, ${ }^{f}$ cerebelo, gponte com pedúnculos cerebelares,

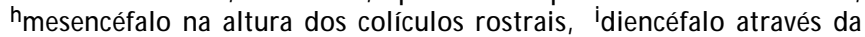
massa intermédia, jlobo frontal na altura do joelho do corpo caloso e dos núcleos da base.

dos outros 7 bovinos examinados (Quadro 2). Esse infiltrado acumulava-se nas leptomeninges e nos espaços perivasculares de Virchow-Robin (Fig. 2). Em todos os casos, o acúmulo perivascular era mais acentuado do quenas leptomeninges. 0 infiltrado inflamatório era constituído por macrófagos epitelióides, linfócitos,

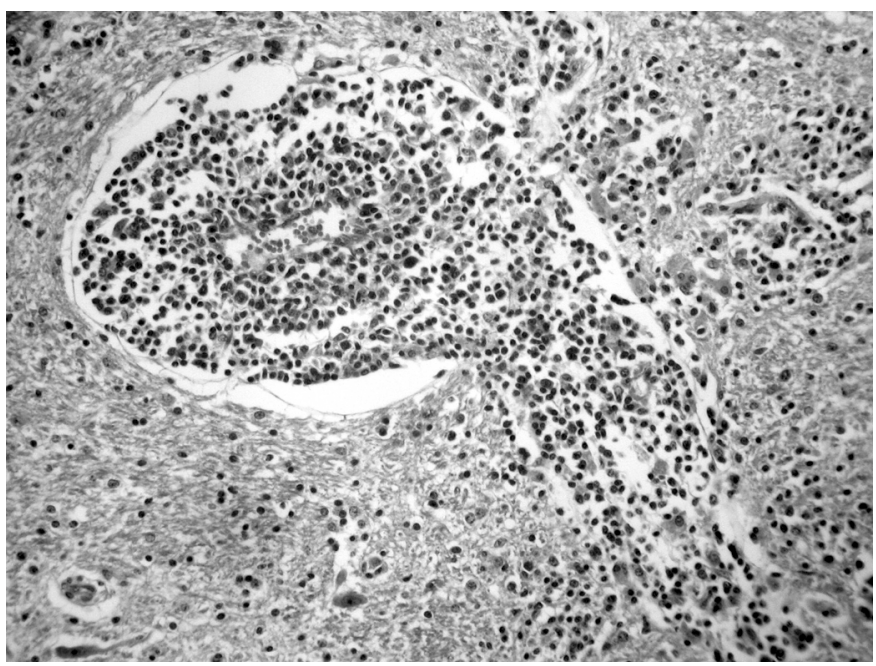

Fig. 2. Meningoencefalite granulomatosa associada ao pastoreio de ervilhaca. Mesencéfalo (Bovino 5). Espesso manguito perivascular formado de linfócitos, plasmócitos, macrófagos epitelióides e eosinófilos. HE, obj. 20.

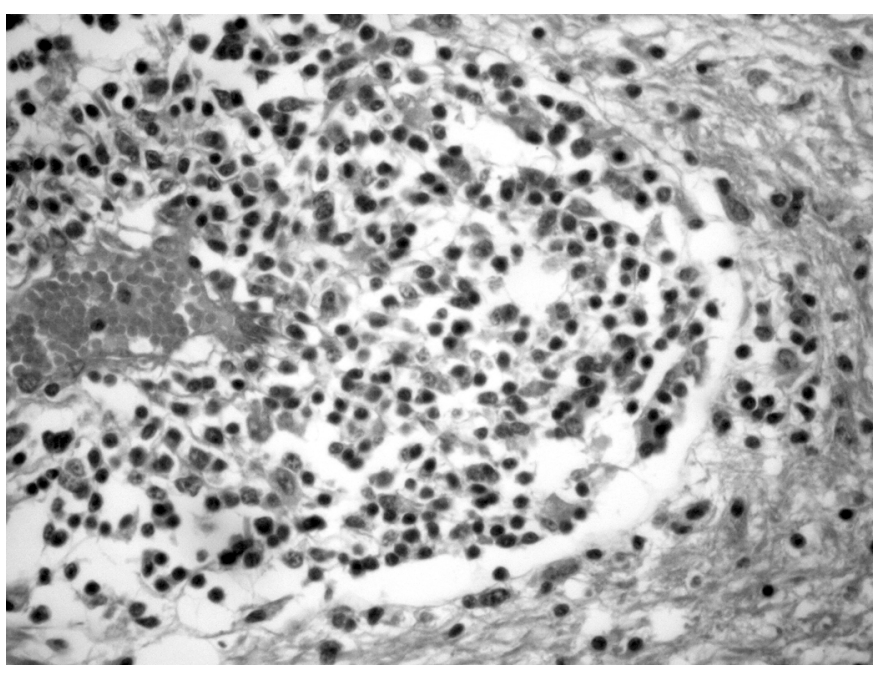

Fig. 3. Maior aumento da figura anterior para mostrar detalhes do infiltrado celular. HE, obj. 40.

plasmócitos e eosinófilos, porém não se observaram células gigantes (Fig. 3). A reação inflamatória foi mais acentuada, em ordem decrescente de intensidade, nos Bovinos 5, 8, 2, 6, 3, 9 e 1. As regiões do encéfalo mais intensamente afetadas, em ordem decrescente de intensidade foram: diencéfalo através da massa intermedia; mesencéfalo na altura dos colícul os rostrais; ponte e pedúnculos cerebelares, bulbo na altura do óbex, lobo frontal na altura do joelho do corpo caloso e cerebelo.

Nos Bovinos 5 e 6, estruturas hialinas de formas variadas, ocasionalmente em forma de gotas, foram observadas e interpretadas como fibrina. Nos cortes da região 4, observou-se lipofuscinose de neurônios do núcleo vermelho do mesencéfalo.

\section{DISCUSSÃO}

Embora não tenham sido associadas a distúrbios neurológicos, as alterações histológicas do encéfalo na DGS ervilhaca- 
asssociada são suficientemente intensas em al guns casos para se constituírem num problema de diagnóstico. Pode ser argumentado que é pouco provável que um laboratório receba para diagnóstico, apenas o encéfalo de um bovino intoxicado por ervilhaca, já que as lesões macroscópicas encontradas na necropsia e em outros órgãos são marcantes e não há sinais clínicos neurológicos associados a essa forma de intoxicação. No entanto, em razão do programa de vigilância para a BSE implantado pelo PNCRH do MAPA, vários laboratórios de diagnóstico do Brasil recebem espécimes de encéfalo fixados em formol de bovino que morreu na propriedade de doença crônica, animal em decúbito ou com doença depauperante - incluídos na Categoria 3 da população de bovinos examinada no programa de vigilância para BSE (Barros \& Marques 2003). Um bovino com DGS ervilhaca-associada, inevitavelmente será incluído nessa categoria e o encéfalo desse animal poderá ser enviado ao laboratório para diagnóstico diferencial. Portanto, é necessário o conhecimento das alterações histomorfológicas que o correm no encéfalo de bovinos com DGS ervilhaca-associada. Essas alterações devem ser diferenciadas de outras meningoencefalites não-supurativas diagnosticadas em bovinos no Brasil como raiva, infecção por herpesvírus bovino-5 (BHV-5), febre catarral maligna, tripanossomíase e tuberculose. Em todas essas condições, as alterações histológicas são características e permitem um diagnóstico preciso. Na raiva, o tipo de lesão é característico de encefalomielite não-supurativa por infecção viral, com degeneração neuronal, gliose nodular e infiltrado mononuclear perivascular; corpúsculos de Negri são encontrados em cerca de 70\%dos casos (Langohr et al. 2003). Na infecção pelo BHV-5, um aspecto distintivo é a extensa necrose neuronal isquêmica (neurônios vermelhos) e, freqüentemente, malacia; os lobos frontais tendem a serem mais afetados (Elias et al. 2004). Na febre catarral maligna, a arterite é a lesão característica, com necrose fibrinóide da túnica média e infiltrado mononuclear na adventícia (Garmatz et al. 2004). Meningite não-supurativa foi observada em al guns casos de tripanossomíase (Trypanosoma vivax) diagnosticados em bovinos no semi-árido do nordeste brasileiro (RietCorrea et al. 2003); esses autores descrevem um infiltrado inflamatório meníngeo, não-granulomatoso, composto de linfócitos. Meningite granulomatosa ocorre esporadicamente em bovinos com tuberculose (Guedes et al. 1997), mas a inflamação consiste usual mente de granulomas cáseo-cal cáreos com células gigantes tipo Langhans, (AFIP 2000); a distribuição da tuberculose meníngea em bovinos predomina na base do encéfalo (meningite basilar tuberculosa) e daí se estende ao tecido nervoso submeníngeo (AFIP 2000). Nos casos de DGS ervilhaca-associada, chama-se à atenção para a distribuição das lesões, 0 aspecto granulomatoso do infiltrado, ausência de células gigantes e a presença de eosinófilos. Quando se dispõe apenas de preparações histológicas para efetuar o diagnóstico, esses aspectos histomorfológicos devem auxiliar na diferenciação da meningoencefalite associada à intoxicação por ervilhaca das outras formas de meningoencefalite comumente encontradas em bovinos adultos.

A lipofuscinose observada em dois bovinos é uma alteração ligada à idade e também sem importância clínica (Summers et al. 1995). As estruturas hialinas interpretadas como fibrina provavelmente resultaram de aumento da permeabilidade vascular relacionada aos eventos inflamatórios. A patogênese das lesões granulomatosas na intoxicação por Vicia spp ainda permanece indeterminada (Panciera et al. 1992, Fighera \& Barros 2004).

\section{REFERÊNCIAS}

AFIP (Armed Forces Institute of Pathology) 2000. 17th Wednesday Slide Conference, Jan.19, Case 1 (AFIP 2687023), enviado pela Universidade Federal de Santa Maria, http://www.afip.org/vetpath/WSC/wsc99/ 99wsc17.htm.

Barros C.S.L., Fighera, R.A, Rozza, D.B., Rech R.R., Sallis S.V. \& Langohr I.M. 2001. Doença granulomatosa sistêmica em bovinos no Rio Grande do Sul associada ao pastoreio de ervilhaca (Vicia spp). Pesq. Vet. Bras. 21:162-171.

Barros C.S.L \& Marques G.H.F. 2003. Procedimentos para o Diagnóstico das Doenças do Sistema Nervoso Central de Bovinos. Depto Defesa Animal, Ministério da Agricultura, Pecuária e Abastecimento (MAPA), Brasília. $50 \mathrm{p}$.

Elias F., Schild A.A. \& Riet-Correa F. 2004. Meningoencefalite e encefalomalacia por Herpes vírus bovino-5 (BHV-5): distribuição das lesões no sistema nervoso central de bovinos naturalmente infectados. Pesq. Vet. Bras. 24(3):123-131.

Fighera R.A. \& Barros C.S.L. 2004. Systemic granulomatous disease in Brazilian cattle grazing pasture containing vetch (Vicia spp). Vet. Human Toxicol. 46:62-66.

Garmatz S.L., Irigoyen L.F., Rech R.R., Brown C.C., Zhang J. \& Barros C.S.L. 2004. Febre catarral maligna em bovinos no Rio Grande do Sul: transmissão experimental para bovinos e caracterização do agente etiológico. Pesq. Vet. Bras. 24:93-106.

Guedes R.M.C., Nogueira R.H.G., Facury Filho E.J. \& Lago L.A. 1997. Meningite tuberculosa bovina. Arqs. Bras. Med. Vet. Zootec. 49:131-135.

Langohr I.M., Irigoyen L.F., Lemos R.A.A \& Barros C.S.L. 2003. Aspectos epidemiológicos, clínicos e distribuição das lesões histológicas no encéfalo de bovinos com raiva. Ciência Rural, Santa Maria 33:125-131.

Panciera R.J. 1978. Hairy vetch (Vicia villosa Roth) poisoning in cattle, p. 555-563. In: Keeler R.F., Van Kampen K.R. \& James L.F. (ed.) Effects of Poisonous Plants on Livestock. Academic Press, New York.

Panciera R.J., Johnson L. \& Osburn B.I. 1966. A disease of cattle grazing hairy vetch pasture. J. Am. Vet. Med. Assoc. 148:804-808.

Panciera R.J., Mosier D.A. \& Ritchey J.W. 1992. Hairy vetch (Vicia villosa Roth) poisoning in cattle: Update and experimental induction of disease. J. Vet. Diagn. Invest. 4:318-325.

Riet-Correa F., Tabosa I.M., Azevedo E.O., Medeiros R.M.T., Simões S.V.D., Dantas A.F.M., Alves C.J., Nobre V.M.T., Athayde A.C.R., Gomes A.A. \& Lima E.F. 2003. Semi-árido em Foco 1(I):49-52. (Universidade de Campina Grande, Campus Patos, Paraíba)

Summers B.A., Cummings J.F. \& De Lahunta A. 1995. Veterinary Neuropathology. Mosby, St. Louis, p.51-52. 